\title{
Image analysis techniques to estimate river discharge using time-lapse cameras in remote locations
}

\author{
David S. Young ${ }^{1}$, Jane K. Hart' ${ }^{2}$, Kirk Martinez ${ }^{1}$ \\ 1 - Electronics and Computer Science, 2 - Geography and Environment, \\ University of Southampton, Southampton, SO17 1BJ, UK \\ email: $\underline{\text { d.s.young@soton.ac.uk, j.k.hart@soton.ac.uk, km@ecs.soton.ac.uk }}$
}

NOTICE: This is the authors' version of a work that was accepted for publication in Computers \& Geosciences. Changes resulting from the publishing process, such as peer review, editing, corrections, structural formatting, and other quality control mechanisms may not be reflected in this document. Changes may have been made to this work since it was submitted for publication. A definitive version was subsequently published in Computers \& Geosciences, 76, 1-10 (2015) doi: 10.1016/j.cageo.2014.11.008

\begin{abstract}
Cameras have the potential to provide new data streams for environmental science. Improvements in image quality, power consumption and image processing algorithms mean that it is now possible to test camera-based sensing in real-world scenarios. This paper presents an 8-month trial of a camera to monitor discharge in a glacial river, in a situation where this would be difficult to achieve using methods requiring sensors in or close to the river, or human intervention during the measurement period. The results indicate diurnal changes in discharge throughout the year, the importance of subglacial winter water storage, and rapid switching from a "distributed" winter system to a "channelised" summer drainage system in May. They show that discharge changes can be measured with an accuracy that is useful for understanding the relationship between glacier dynamics and flow rates.
\end{abstract}

Keywords: Remote sensing; river discharge; glacial melt; time-lapse camera; image analysis; flow rate monitoring.

\section{Introduction}

Recent developments in digital photography have allowed opportunities for ground-based camera monitoring of the environment. These have the potential to be part of a wireless environmental sensor network (Hart and Martinez, 2006; Kulkarni et al., 2007), a device within an Internet of Things (IoT) system (Ward et al., 2014; Zhang, 2011) or a stand-alone device. Digital cameras are generally low cost, robust, easy to install and can provide high quality environmental data. These advantages are especially important in remote areas.

Here we describe the installation, image processing and preliminary results for a pilot system to estimate discharge from a glacier-fed river at Skálafellsjökull, Iceland over a year. This camera was 
installed as part of the Glacsweb sensor network system (Martinez et al., 2004, 2009), whose aim is to study glacier dynamics.

Most existing work on river discharge measurement is either based on satellite/aerial images (Smith, 1997; Brakenridge et al., 2007; Marcus and Fonstad, 2010) or on detailed surface shape/flow velocity measurements, e.g. particle image velocimetry (Bradley et al., 2002; Hauet et al., 2008; Bird et al., 2010; Tsubaki et al., 2011). The latter requires markers and may involve the use of stereo cameras. By contrast we focus on results from a simple time-lapse image stream from an inexpensive fixed camera. The results indicate that this system provides a useful, low cost way to monitor discharge in remote locations.

\section{Field site}

The study was undertaken at Skálafellsjökull, Iceland ( $64^{\circ} 15^{\prime} 28.22^{\prime \prime} \mathrm{N}, 15^{\circ} 50^{\prime} 37.44^{\prime \prime}$ W), an outlet glacier of the Vatnajökull icecap (Figure 1). This glacier has an area of approximately $100 \mathrm{~km}^{2}$ and is $25 \mathrm{~km}$ in length (Sigurðsson, 1998). An environmental sensor network was deployed, consisting of multiple heterogeneous nodes which have been developed during several years of continuous deployments (Martinez et al., 2004, 2009, 2012). Sensor nodes on and in the glacier use appropriate radio frequencies to communicate to a base station. This in turn uses a nearby Wi-Fi gateway node to communicate out to the cloud server. These gateways act as routing nodes and include dGPS receivers, a meteorological station, cameras and other diagnostic sensors.

The main study site was located on the southern side of the glacier at an elevation of $792 \mathrm{~m}$ a.s.l. The main portal (from which the glacier melt water drained) is located approximately $3000 \mathrm{~m}$ away, at an outlet of the main glacier called the Sultartungnajökull tongue, at an elevation of $400 \mathrm{~m}$ a.s.l. A bridge is located approximately $500 \mathrm{~m}$ from the glacier margin, spanning the outlet river. This river comprises a mostly single thread stream approximately 1-8 $\mathrm{m}$ wide, depending on the state of flow, with a very coarse boulder bed. The camera, at $64^{\circ} 14^{\prime} 20.83^{\prime \prime} \mathrm{N}, 15^{\circ} 48^{\prime} 49.33^{\prime \prime} \mathrm{W}$ and altitude 344 $\mathrm{m}$ a.s.l., is mounted on the bridge (Figure 2).

The camera was a Brinno TLC100, an inexpensive time-lapse camera designed for unattended outdoor battery-powered operation ${ }^{1}$. It can capture up to 28,000 frames of $1280 \times 1024$ pixels, stored on a USB flash drive as an AVI file with MJPEG compression, and has a fixed field of view of approximately $50^{\circ}$ on the diagonal. Two main sequences were recorded: the first, at one-minute intervals, covered three days from 23 to 26 September 2012 (day of year, DOY 267-270) and was analysed at 15 minute intervals; the second, at 4-hour intervals, covered the period from 22 October 2012 (DOY 296) to 6 June 2013 (DOY 157). In addition we used a single hand held image from the same location (16th July 2013, DOY 197) to extend the data span. In all cases, images were missing when the light level was too low for effective capture. For a substantial part of the second sequence, the course of the river was covered with snow. Typical images for a variety of states of the river are shown in Figure 3.

\footnotetext{
${ }^{1}$ http://www.brinno.com/html/TLC100.html downloaded 14 January 2014
} 


\section{Image processing Techniques}

\subsection{Overall approach}

The main goal of the image processing is to make an estimate of the river discharge for each image in which water was visible. Secondary estimates were also made of fog and snow cover.

For most rivers, discharge $(Q)$ cannot be measured directly, but is calculated from measurements of the volumetric flow rate through a cross-section:

$$
Q=V A
$$

where $V$ is the average velocity, and $A$ is the cross-sectional area perpendicular to the flow. Although accurate absolute values of discharge are very difficult to attain for mountain streams (Bathurst, 1985; Chen, 2013), effective relative measurements may be obtained from variations in the depth and width of the water. Our overall approach is therefore to measure the positions of the visible water margin at various points in each image, and to combine these with a simple model of the shape of the river bed and its hydraulic properties. The resulting flow estimates will have large systematic errors due to the simplifications of the model, but the random error can be kept low enough to allow temporal correlations between the flow and other events to be investigated with high confidence.

The position of the edge in the image corresponding to the water margin was measured in a number of regions of interest, each chosen so that there was a clear edge for most states of flow (Figure 4). The water edge was either on a roughly vertical rock surface facing the camera, or on a sloping area of the bank. The edge positions, expressed in image coordinates for each frame of the sequence, formed the data for flow estimation. The image processing thus fell into two main sections: finding the image coordinates of the water margins, and combining these coordinates into a flow estimate.

\subsection{Water margin image measurements}

Ideally, the images would be processed fully automatically to segment the water and bank regions and hence find water margin positions. This could not be done reliably for these images for a number of reasons:

- There are strong illumination changes between frames. These result from the sun's motion through the day and changes in meteorological conditions.

- Hue changes between the water and the banks are not strong or consistent, and the hue channel of the images is strongly affected by compression artefacts.

- Some frames are affected by raindrops on the camera lens, snow on the ground, and fog.

- The complex and varied textures of the rocky and gravel-covered banks, and of the turbulent water, make texture discrimination difficult and edge detection ambiguous.

In view of these factors, we adopted a manually supervised method. Each image was processed using a Canny edge detector (Canny, 1986) and the edges in each region of interest were displayed. If a clear edge segment corresponding to the water margin was visible, this was selected using the 
mouse. A second-degree polynomial was fitted to the pixels of the segment to accurately locate the position of the water edge (Figure 5). Where there was no clear edge at the water margin, no position was recorded. This procedure requires about two days' work for one person to process a year's worth of data at 4-hour intervals, including flagging images showing snow cover, rain and mist.

The camera was fixed to a rigid structure, but some camera movement was apparent in the image sequence. This may be attributable to thermal expansion of the bridge structure and the effects of wind, rain and vehicle vibrations on the camera mountings. The camera motion was measured by tracking image features from frame to frame using normalised cross-correlation (Haralick and Shapiro, 1993) and fitting a translation and rotation by least squares to each of the resulting optic flow fields. Successive image pairs were used (rather than matching each image with the same reference image) to reduce the effects of major changes such as snowfall on the tracking function. Cumulative errors were removed by tracking features directly between the first and last images of the sequence, which were both largely clear of snow. The discrepancy between this measurement and the cumulated pairwise measurements was removed by distributing the difference linearly across the sequence. Corrections to compensate for the camera movements were then applied to the edge positions.

Each edge position was represented by a single coordinate. For a region of interest on a boulder face, this was the image $y$-coordinate, measured at a fixed $x$-coordinate after correction for camera movement; for a riverside region it was the $x$-coordinate measured at a fixed $y$-coordinate.

The presence of snow, fog, rain on the camera lens, and ice at the edges of the river was manually recorded for each frame. An estimate of the density of fog was also made automatically by smoothing the image using a Gaussian kernel at two spatial scales. The local grey-level variance at each pixel was computed for each smoothed image and the average ratio of the variances, found at a set of image features, taken as a measure of the density of the fog. This is effective because smoothing reduces the variance much more when the image is clear than when it is already blurred by fog.

\subsection{Edge measurement combination}

We adopt a simple V-shaped model of the river channel, so that the width and height of the water cross-section are linearly related. Each of the water edge image coordinates is also approximately linearly related to the width or height. We can derive an overall measure of river height by a method closely related to Principal Component Analysis.

The central assumption is that each edge coordinate is linearly related to the height of the water surface. If the measured coordinate for region $i$ at time $t$ is $y_{i t}$, we assume that

$$
y_{i t}=k_{i} h_{t}+c_{i}+N_{i t}
$$

where $h_{t}$ is the height of the water above some arbitrary datum, measured in arbitrary units, $k_{i}$ and $c_{i}$ are parameters associated with this image region, and $N_{i t}$ is a random noise variable. 
Geometrically, this corresponds to assuming that river bank measurements are made on planar surfaces, that boulder surfaces are planar or boulder measurements are made where the line of sight is at a small angle to the water surface or to the river margin, and that the water surface is planar (Figure 6). All of these are violated to some degree, but redundancy in the measurements allows us to check for consistency.

To estimate the model parameter vectors $k$ and $c$, we work with the data for times for which all the measurements are available, that is, there is a clear edge in every region. Choosing $h$ to have zero mean, we estimate $c_{i}$ as the mean over time of $y_{i t}$. We then find the least-squares fit of a rank-1 matrix to $\left(y_{i t}-c_{i}\right)$ using the singular value decomposition (SVD) (Horn and Johnson, 2012). The best-fit matrix can be factorised into the product of a column vector with elements $k_{i}$ and a row vector with elements $h_{t}$. We arbitrarily choose the norm of $h$ to be unity.

The residuals $y_{i t}-\left(k_{i} h_{t}+c_{i}\right)$ allow estimates of the noise for each measurement region:

$$
s_{i}=\sqrt{\frac{1}{n} \sum_{t}\left[y_{i t}-\left(k_{i} h_{t}+c_{i}\right)\right]^{2}}
$$

where $n$ is the number of time points and $s_{i}$ is an estimate of the standard deviation of the noise for the $i^{\prime}$ th coordinate. To improve the accuracy of the parameter estimates, we then repeat the SVD after multiplying the rows of $y$ by their inverse standard deviations; this performs a weighted leastsquares fit. This procedure may be iterated; empirically, we find that one or two iterations achieve most of the reduction in the estimated s.d.

We make a final estimate of the scaled river height $h$ using an inverse-variance weighted mean. From Equation [2] we have that the best estimate of $h_{t}$ from measurement $y_{i t}$ is $h_{t}=\left(y_{i t}-c_{i}\right) / k_{i}$, and its estimated variance is therefore $\left(s_{i} / k_{i}\right)^{2}$, giving for the overall estimate

$$
\begin{gathered}
h_{t}=\frac{\sum_{i}\left(\frac{y_{i t}-c_{i}}{k_{i}} \cdot \frac{1}{\left(s_{i} / k_{i}\right)^{2}}\right)}{\sum_{i} \frac{1}{\left(s_{i} / k_{i}\right)^{2}}} \\
=\frac{\sum_{i}\left(y_{i t}-c_{i}\right) k_{i} / s_{i}^{2}}{\sum_{i}\left(k_{i} / s_{i}\right)^{2}} .
\end{gathered}
$$

The estimate $h_{t}$ represents the river height in arbitrary units above an arbitrary datum. We chose the constants in Equation [1] such that $h$ has zero mean and unit norm; we need additional information to fix the origin and scale if we wish to estimate the river dimensions in known units.

Not every region of interest had a clear edge in every frame, because of rain, snow, a lack of contrast between the water and the rocks, or because the water level was too high or too low for the surface. In these cases an estimate of $h_{t}$ was made by taking the sum in Equation [4] over the available edges. The standard deviation of each estimate was also obtained using

$$
s_{t}=\left[\sum_{i}\left(k_{i} / s_{i}\right)^{2}\right]^{-1 / 2}
$$

where again the sum is over available measurements. 


\subsection{Random errors and data consistency}

Using Equation [3], we obtain estimates of the random errors in the edge image coordinates. The estimated standard deviation $s_{i}$ for each image region is given in Table 1 . Note that these are estimated standard deviations of the noise distributions, not the sample standard deviations of the measurements themselves, and they reflect the validity of the linearity assumption and random perturbations of the measurements. The measurements on boulder surfaces, and in the more distant region of interest on the right bank, are consistent to less than 5 pixels. The remaining two regions show much larger errors, and it is likely that these occur because the banks are irregular in these areas, with substantial changes in slope in causing jumps in position as the river rises and falls.

The second column of Table 1 shows the normalised scaling factors $k_{i}$ of Equation [2]. As expected, the factors for the boulder surfaces are smaller than for the banks, with the exception of the near region on the right bank. This region was chosen because the bank looked smooth, but the data demonstrate that the edge position does not move as expected with changing level. It is likely that in fact there is a narrow and relatively steep-sided channel at this point, in which the flow is confined except at times of high water.

The third column of Table 1 shows the relative contribution each region makes to the weightedmean flow estimate. Because it has both good sensitivity to the water level and a low standard deviation, region 2 on the right bank dominates the result whenever it is available. On the other hand, region 5 on the right bank makes a very small contribution; it is automatically neglected because it fails to fit the linear model. The two boulder surfaces provide additional useful information and are important if the edge in region 2 is not clear.

The noise level in the scaled height estimate $h_{t}$ can be obtained from Equation [5]. When all 5 measurements are available, the noise variance of $h_{t}$ is 0.03 , but when fewer measurements are available this increases. Since an error estimate is available for each frame, it is straightforward to filter the resulting time series to only include well-supported values.

\subsection{Camera and river geometry}

To estimate the rate of flow, we need to carry out a calibration that relates $h_{t}$ to the actual width and depth of the river. We assume a V-shaped river bed so that width will be a linear function of $h$. To estimate the parameters of this function we need estimates of the width for at least two different states of flow, and this in turn requires a camera and scene model that allows 3-D positions to be obtained from 2-D image coordinates.

Given the difficult terrain and limited resources in a remote area, our calibration was necessarily based on minimal information. A single image of a $1 \mathrm{~m}$ measuring tape held approximately normal to the line of sight and close to the river was available. The focal length of the Brinno camera was estimated from the manufacturer's literature and checked by comparison with an image taken by another camera of known focal length. Thus an estimate of the depth (the distance from the camera) of one point in the scene was available. 
To obtain an estimate of the downstream slope of the river bed, it was necessary to georeference the camera images. Although the position of the camera was accurately known, its orientation had not been recorded. Fortunately, the shadow of the bridge and of the support to which the camera was attached was visible in several images. The azimuth and elevation of the sun are easily computed for these image times, thus giving a known direction for some image points. Hence the azimuth and elevation of the optical axis of the camera can be found, which together with the known location allowed the images to be registered to satellite images, aerial photographs, maps and digital elevation models (Figure 7).

Given this precise registration, an estimate of the average gradient of the river in the observed region was made using the ASTER GDEM ${ }^{2}$. Hence the angle between the optic axis of the camera and the planar approximation to the water surface over the main observed stretch of river could be estimated. The camera axis was $9.6^{\circ}$ below the horizontal, the downstream slope of the river bed was $7.5^{\circ}$, and the line of sight thus made an angle of about $16^{\circ}$ with the river surface. Together with the single distance estimate, this is sufficient information to estimate the homography between the images and a plane approximated by the river surface (Hartley and Zisserman, 2004). The homography parameters were checked by projecting the Cnes/Spot image of the area into the camera view and comparing this with the camera images.

Calibration now proceeded as follows. For four different states of the river we measured the image coordinates of the water margins and transformed these into positions on the river surface plane. From these the average width $w$ of the reach was computed using the homography, and a linear function was fitted to the $h, w$ pairs. Applying the linear function to values of $h_{t}$ gives a calibrated estimate of the river width for every image that yielded edge positions.

For the same times, the relative water height was estimated directly from measurements of the level on a boulder face. The homography allows us to estimate the boulder's distance from the camera, and this together with the focal length of the camera, the assumption described in Figure 6, and the change in vertical image coordinate give calibrated changes in water height. In the case of the nearer boulder in Figure 4, each image pixel corresponds to about $1 \mathrm{~cm}$ water depth.

The average cross-river slope of the banks was obtained by fitting a linear model to the water height versus the river width at different states of flow. This process can also be viewed as using the ratio of the factors $k_{i}$ for vertical and horizontal coordinates, adjusted by the relative distances of the regions of interest. In this case, the slope was about $5^{\circ}$.

\subsection{Discharge estimation}

Given our simplified geometry and measurements of the river surface width, we can approximate the discharge. A variety of methods are available, but for a mountain river such as this all have high levels of uncertainty. We therefore adopt a commonly-used model to give order-of-magnitude estimates of discharge. This is likely to introduce systematic errors into the discharge estimates, but

\footnotetext{
${ }^{2}$ Aster granules ASTGTM2_N64W016 and ASTGTM2_N64W017. ASTER GDEM is a product of METI and NASA.
} 
we can quantify the random error of each estimate using the derivative of the discharge function with respect to width. We can therefore assess the accuracy of the relative magnitude of changes in the discharge whilst noting that there is an unknown systematic error in the individual numerical values. This is sufficient to allow models of the temporal behaviour of the glacier to be developed and tested against data using temporal correlations.

We adopt the Glauckler-Manning equation for average velocity $V$

$$
V=\frac{1}{n} R_{h}^{2 / 3} S^{1 / 2}
$$

where $n$ is Manning's constant, which we take as 0.04 for this river, $R_{h}$ is the hydraulic radius and $S$ is the downstream slope (McCutcheon, 1990). The hydraulic radius for our V-shaped model is given by

$$
R_{h}=g w /\left(4 \sqrt{1+g^{2}}\right)
$$

where $g$ is the bank gradient and $w$ is the river surface width. Hence using Equation [1] we have our overall estimate for the discharge $Q$ :

$$
Q=\left(\frac{g}{4}\right)^{5 / 3} \frac{S^{1 / 2}}{n\left(1+g^{2}\right)^{1 / 3}} w^{8 / 3}
$$

This is easily differentiated to obtain estimates of the standard deviation of $Q$ from the standard deviation of $h$.

The main output of the process is thus a time series of flow estimates, together with estimates of their random errors. This is made available for further analysis by export to, for example, a spreadsheet, and also through a graphical user interface that gives a linked display of a plot of the flow and of the image that gave rise to each point.

\section{Case Study}

\subsection{Glaciological context and data coverage}

The movement of water through the glacier determines glacier velocity and the rate at which glaciers can respond to climate change. The water in glacial rivers is generated from: (i) surface meltwater (due to air temperature and rainfall) passing through the glacier (via conduits, crevasses, moulins and cavities) into the subglacial drainage system; and (ii) frictional heating due to glacier movement (which itself is controlled by water at the ice and the glacier base). The river flow is measured close to the glacier and between the glacier and the measurement site the river is confined to a narrow rocky channel with no tributaries. We therefore expect that contributions from groundwater and rainfall into the river valley below the glacier will be negligible.

The typical annual pattern of glacier rivers includes: high levels of summer discharge with diurnal variation; a reduction in flow during the winter; dramatic discrete "spring-events" when the glacier rapidly advances. It is argued this pattern is because during the summer there is a "channelised", or 
"fast" drainage system of connected arborescent channels fed by high volumes of meltwater. During the winter and spring, there is insufficient water to maintain such a system and instead there is a "distributed" or "slow" drainage system of non-arborescent channels (Iken and Binschadler, 1986; Willis et al., 1990; Harbor et al., 1997; Fountain and Walder, 1998).

The results for the whole year are shown in Figure 8. We have determined the study periods a follows: Late Summer (day-of-year 267-290), Autumn (DOY 291-4), Winter (DOY 5-64), Spring (DOY 131-144) and Early Summer (DOY 145-196). Although the data for most of the study period was taken at 4 hour intervals, due to the high latitude location of the site the number of images visible varied from only one per day in mid-winter to all six in mid-summer. Table 2 shows the times of day at which there was generally enough light to record images and the percentage of these images for which a river discharge was estimated. The weather in these periods determined the percentage of clear images. The available data coverage was good during DOY 296-321, DOY 355-15, and DOY 140157. However, during DOY 322-354 and DOY 16-139 the available data coverage was much lower due to fog and/or snow cover. Temperature data is available for the whole year, measured at the glacier base station, and also at the Icelandic Meteorological Station at Hofn, $30 \mathrm{~km}$ away at sea level.

\subsection{Diurnal pattern}

Figure 9a shows the average of the diurnal temperature and discharge over the different seasons. It can be seen that there is a diurnal pattern throughout the year which has the greatest range in spring and summer, and least in autumn and winter. A typical glacial meltwater pattern is for low flow in the night and early morning, then for temperatures and discharge to rise throughout the morning reaching a peak in the afternoon, followed by a slow decline throughout the evening. There is usually a lag in the system as it takes time for the water to reach the proglacial river (Rothlisberger and Lang, 1987). A summer example is shown in Figure $9 \mathrm{~b}$ for 2 days in June 2013 with data from all six periods. On DOY 152, the peak in both temperature and discharge occurs at 17:00, whilst the minimum discharge occurs the following morning is at 09:00, 4 hours after the minimum temperature. We interpret this as showing that there is rapid flow through the glacier, but at the same time a slower storage element that may continue to supply water to the river after the main peak has passed.

Figure 9c shows the 15 minute data in September 2012 (the night discharge data is not available because of the darkness). On DOY 268 the peak discharge (12:15) is similar to the peak in air temperature, and there is a positive relationship between air temperature and discharge after midday. However, DOY 269 and 270 show a very different pattern. Although the maximum temperature peak is at a similar time to maximum discharge and minimum discharge is in the morning, there is a much lower discharge, and a very stable afternoon discharge (with no relationship to temperature). There is also a dramatic rise in discharge which occurs between 12.00 and 12.15 .

The main difference between DOY 268 and DOY 269/270 are the very cold preceding nights. When the temperature goes below zero there will be no melting, and discharge will only come from frictional heating. We suggest that the cold night of DOY 268/269 caused storage within the glacier 
to begin to drain, and when temperatures rose on DOY 269 meltwater was very rapidly transported through the glacier (in 15 minutes), with a similar pattern in DOY 270. This indicates that there is very "fast" well connected drainage within the glacier, as well as a "slow" storage element that can easily be drained.

\subsection{Autumn and Winter flow}

With reference to Figure 8 , it can be seen that discharge continues throughout the autumn and winter (DOY 291-64), with some of the highest discharges in February (Figure 3). From DOY 292 onwards average daily temperatures are constantly negative, but there are a few days when temperatures rise above (or are close to) zero. Peaks in discharge occur on average 2 days after these warm events (e.g. DOY 361, DOY 10). In addition, there is a relationship between the number of continuous positive degree days and the discharge. The highest discharge on DOY 56 occurs after the longest "warm" period during the winter months.

This shows that storage is very important during this part of the year. Water produced from creep must be collected in storage within the glacier, until a melt water event, when "fast" flow brings discharge into the river. This fast flow must cause bed separation, allowing the water to be removed from storage.

\subsection{Spring to Summer transition}

There is a good record from DOY 131-157 (Figure 8). However, there is a marked change on DOY 144 from relatively low discharge (mean 0.69 , s.d. 0.15 ) and temperatures (mean $1.66^{\circ} \mathrm{C}$, s.d. 1.28 ) to much higher discharge (mean 2.41 , s.d. 0.38 ) and temperatures (mean $3.34^{\circ} \mathrm{C}$, s.d. 1.22 ). The first part of the time not only has lower daily temperatures, but includes times when temperatures go below zero at night.

The transition between these two periods is very dramatic occurring between 13:00 and 17:00 on DOY 144. Once the transition occurred flow was consistently high for three days (even at night) before returning to a diurnal pattern. We would argue that prior to this event the water was being added to storage. This has continued to build up until DOY 144 when we propose bed separation occurred, water was able to be discharged from the glacier, and the subglacial river system changed from "distributed" to "channelized". This "Spring" event is analogous to that seen in many glacial environments.

\subsection{Link between discharge and temperature}

Figure 10 shows the relationship between air temperature and discharge. During the summer there is a positive correlation, but this is not the case for the rest of the year. This is because once the channelized system is established in the summer, more water is generated by warmer weather and can be easily removed from the system. During the rest of the year when there is a distributed system, most of the water generated from glacier movement is kept in storage, until warm days when "fast" flow within the system promotes increased drainage. 


\section{Discussion}

It is difficult and expensive to obtain conventional discharge estimates for a river like the one studied here. The remote location and difficult terrain make access uncertain or impossible at some times of year. Satellite and high-level aerial images offer too little resolution, both spatial and temporal, whilst unmanned aerial vehicles do not at present offer the possibility of long-term monitoring. Physical installations such as turbine flow meters or gauging boards are likely to be destroyed in flood conditions unless serious engineering is undertaken, and flow-metering weirs require even greater investment in a single site. These problems are compounded when monitoring of a number of rivers in an area is needed.

This study demonstrates that by deploying cheap, robust and easily installed cameras, we can make scientifically useful estimates of river discharge at low cost. We require only a reasonably stable mounting point with a clear view of the river. Careful image analysis offers discharge measures with quantifiable random errors, allowing investigation of temporal correlations.

There are two main disadvantages to this approach. The first is that large systematic errors are present in the flow estimates due to the simple hydraulic model. These mean that flow rates for different rivers cannot be reliably compared, and the absolute values are likely to be incorrect by an unknown factor. However, this does not reduce the value of the measurements for investigations that look at patterns of change over time and so rely on relative values. The second disadvantage is that fog, and to a lesser extent rain and snow, obscure the camera's view and may lead to an incomplete record.

There is thus a trade-off between cost and ease of installation on one hand, and knowledge of the scaling function for the flow and the completeness of the data record on the other. We propose that for many scientific applications this trade-off will favour the use of simple time-lapse camera systems, augmented by careful image analysis techniques.

\section{Acknowledgements}

The authors would like to thank the Glacsweb team (in particular Philip Basford, Thomas Bishop, Graeme Bragg, Alexander Clayton, Andrew Turner and Tyler Ward) for data collection. Thanks also to Mark Dover (Cartographic Services, Geography and Environment) for figure preparation. This research was funded by the Leverhulme Trust (grant number F/00 180/AK) and ARM, United Kingdom.

\section{References}

Bathurst, J.C., 1985. Flow Resistance Estimation in Mountain Rivers. Journal of Hydraulic Engineering 111(4), 625-643

Bird, S., Hogan, D., Schwab, J., 2010. Photogrammetric monitoring of small streams under a riparian forest canopy. Earth Surface Processes and Landforms 35(8), 952-970

Bradley, A.A., Kruger, A., Meselhe, E.A., Muste, M.V.I., 2002. Flow measurement in streams using video imagery. Water Resources Research 38(12), 1315. doi:10.1029/2002WR001317 
Brakenridge, G.R., Nghiem, S.V., Anderson, E., Mic, R., 2007. Orbital microwave measurement of river discharge and ice status. Water Resources Research 43(4), W04405.

doi:10.1029/2006WR005238

Canny, J., 1986. A Computational Approach to Edge Detection. IEEE Transactions on Pattern Analysis and Machine Intelligence 8(6), 679-698

Chen, Y.-C., 2013. Flood discharge measurement of a mountain river - Nanshih River in Taiwan. Hydrology and Earth System Sciences 17, 1951-1962. doi:10.5194/hess-17-1951-2013

Fountain, A.G., Walder, J.S., 1998. Water flow through temperate glaciers. Reviews of Geophysics 36(3), 299-328. doi:10.1029/97RG03579

Haralick, R.M., Shapiro, L.G., 1993. Computer and Robot Vision, Volume II. Addison-Wesley, Reading, MA, 630pp.

Harbor, J., Sharp, M., Copland, L., Hubbard, B., Nienow, P., Mair, D., 1997. Influence of subglacial drainage conditions on the velocity distribution within a glacier cross section. Geology 25(8), 739742. doi:10.1130/0091-7613(1997)025<0739:IOSDCO>2.3.CO;2

Hart, J.K., Martinez, K., 2006. Environmental sensor networks: a revolution in the earth system science? Earth-Science Reviews 78(3-4), 177-191

Hartley, R., Zisserman, A., 2004. Multiple View Geometry in Computer Vision, 2nd edn. Cambridge University Press, Cambridge, 670pp.

Hauet, A., Kruger, A., Krajewski, W., Bradley, A., Muste, M., Creutin, J., Wilson, M., 2008.

Experimental system for real-time discharge estimation using an image-based method. Journal of Hydrologic Engineering 13(2), 105-110. doi:10.1061/(ASCE)1084-0699(2008)13:2(105)

Horn, R.A. and Johnson, C.R., 2012. Matrix Analysis, 2nd edn. Cambridge University Press, Cambridge, 662pp.

Iken, A., Bindschadler, R.A., 1986. Combined measurements of subglacial water pressure and surface velocity of Findelengletscher, Switzerland: conclusions about drainage system and sliding mechanism. Journal of Glaciology 32(110), 101-119

Kulkarni, P., Shenoy, P., Ganesan, D., 2007. Approximate initialization of camera sensor networks. In: Langendoen, K., Voigt, T. (Eds) Wireless Sensor Networks, 4th European Conference, EWSN 2007, Delft, The Netherlands. Published in: Lecture Notes in Computer Science, Vol. 4373, Springer, Berlin, Heidelberg, pp 67-82. doi:10.1007/978-3-540-69830-2_5

Marcus, W.A., Fonstad, M.A., 2010. Remote sensing of rivers: the emergence of a subdiscipline in the river sciences. Earth Surface Processes and Landforms 35(15), 1867-1872. doi:10.1002/esp.2094

Martinez, K., Hart, J.K., Ong, R., 2004. Environmental sensor networks. Computer 37(8), 50-56. doi:10.1109/MC.2004.91

Martinez, K., Hart, J.K., Ong, R., 2009. Deploying a wireless sensor network in iceland. In: Trigoni, N., Markham, A., Nawaz, S. (Eds) GeoSensor Networks, Third International Conference, GSN 2009, 
Oxford UK. Published in: Lecture notes in Computer Sciences, Vol. 5659, Springer, Berlin, Heidelberg, pp 131-137. doi:10.1007/978-3-642-02903-5_13

Martinez, K., Basford, P.J., de Jager, D., Hart, J.K., 2012. A wireless sensor network system deployment for detecting stick slip motion in glaciers. In: IET Conference on Wireless Sensor Systems (WSS 2012), pp 1-3. doi:10.1049/cp.2012.0580

McCutcheon, S.C., 1990. Water Quality Modeling: River Transport and Surface Exchange, Volume 1. CRC Press, London, 344pp.

Roethlisberger, H., Lang, H., 1987. Glacial hydrology. In: Gurnell, A.M., Clark, M.J. (Eds) Glacio-Fluvial Sediment Transfer: An Alpine Perspective. John Wiley and Sons, Chichester, UK, pp 207-284.

Sigurðsson, O., 1998. Glacier variations in Iceland 1930-1995. Jökull 45, 3-25

Smith, L.C., 1997. Satellite remote sensing of river inundation area, stage, and discharge: a review. Hydrological Processes 11(10), 1427-1439. doi:10.1002/(SICI)1099-1085(199708)11:10<1427::AIDHYP473>3.0.CO;2-S

Tsubaki, R., Fujita, I., Tsutsumi, S., 2011. Measurement of the flood discharge of a small-sized river using an existing digital video recording system. Journal of Hydro-environment Research 5(4), 313321. doi:10.1016/j.jher.2010.12.004

Ward, T., Martinez, K., Chown, T., 2014. Simulated analysis of connectivity issues for sleeping sensor nodes in the internet of things. In: Proceedings of the 11th ACM Symposium on Performance Evaluation of Wireless Ad Hoc, Sensor, \& Ubiquitous Networks, ACM, New York, NY, pp. 101-108. doi:10.1145/2653481.2653490

Willis, I.C., Sharp, M.J., Richards, K.S., 1990. Configuration of the drainage system of Midtdalsbreen, Norway, as indicated by dye-tracing experiments. Journal of Glaciology 36(122), 89-101

Zhang, L., 2011. An IOT system for environmental monitoring and protecting with heterogeneous communication networks. In: 2011 6th International ICST Conference on Communications and Networking in China (CHINACOM), pp 1026-1031. doi:10.1109/ChinaCom.2011.6158307 


\section{Tables}

Table 1 Random error estimates and weighting factors for edge positions in the regions of interest shown in Figure 4. Regions are numbered from the top of the figure downwards.

\begin{tabular}{|l|l|l|l|}
\hline Region & $\begin{array}{l}\text { S.D. } \\
\text { (pixels), } \\
s_{i}\end{array}$ & $\begin{array}{l}\text { Linear } \\
\text { coefficient, } \\
k_{i}\end{array}$ & $\begin{array}{l}\text { Contribution to final } \\
\text { estimate, } \\
k_{i} / s_{i}{ }^{2} / \sum_{i}\left(k_{i} / s_{i}{ }^{2}\right)\end{array}$ \\
\hline 1 - boulder surface & 5.2 & 0.068 & 0.0477 \\
\hline $2-$ right bank & 3.5 & 0.574 & 0.8636 \\
\hline $3-$ left bank & 23.6 & 0.246 & 0.0083 \\
\hline $4-$ boulder surface & 4.5 & 0.083 & 0.0758 \\
\hline $5-$ right bank & 11.1 & 0.030 & 0.0046 \\
\hline
\end{tabular}

Table 2 Image times and percentage data coverage during the continuous $\mathbf{4}$ hour recording $22^{\text {nd }}$ October 2012 to $6^{\text {th }}$ June 2013

\begin{tabular}{|l|l|l|l|l|l|l|l|}
\hline Times & $\begin{array}{l}\text { DOY } \\
296-321\end{array}$ & $\begin{array}{l}\text { DOY } \\
322-354\end{array}$ & $\begin{array}{l}\text { DOY } \\
355-15\end{array}$ & $\begin{array}{l}\text { DOY } \\
16-88\end{array}$ & $\begin{array}{l}\text { DOY } \\
89-96\end{array}$ & $\begin{array}{l}\text { DOY } \\
97-139\end{array}$ & $\begin{array}{l}\text { DOY } \\
140-157\end{array}$ \\
\hline 01.10 & & & & & & & $\checkmark$ \\
\hline 05.10 & & & & & $\checkmark$ & $\checkmark$ & $\checkmark$ \\
\hline 09.10 & $\checkmark$ & $\checkmark$ & & $\checkmark$ & $\checkmark$ & $\checkmark$ & $\checkmark$ \\
\hline 13.10 & $\checkmark$ & $\checkmark$ & $\checkmark$ & $\checkmark$ & $\checkmark$ & $\checkmark$ & $\checkmark$ \\
\hline 17.10 & $\checkmark$ & & & $\checkmark$ & $\checkmark$ & $\checkmark$ & $\checkmark$ \\
\hline 21.10 & & & & & & $\checkmark$ & $\checkmark$ \\
\hline$\%$ data coverage & $68 \%$ & $31 \%$ & $69 \%$ & $37 \%$ & $0 \%$ & $21 \%$ & $93 \%$ \\
\hline
\end{tabular}




\section{Figures}

Figure 1

Map of the study area. The square indicates the main Glacsweb study site, and the star indicates the camera location.
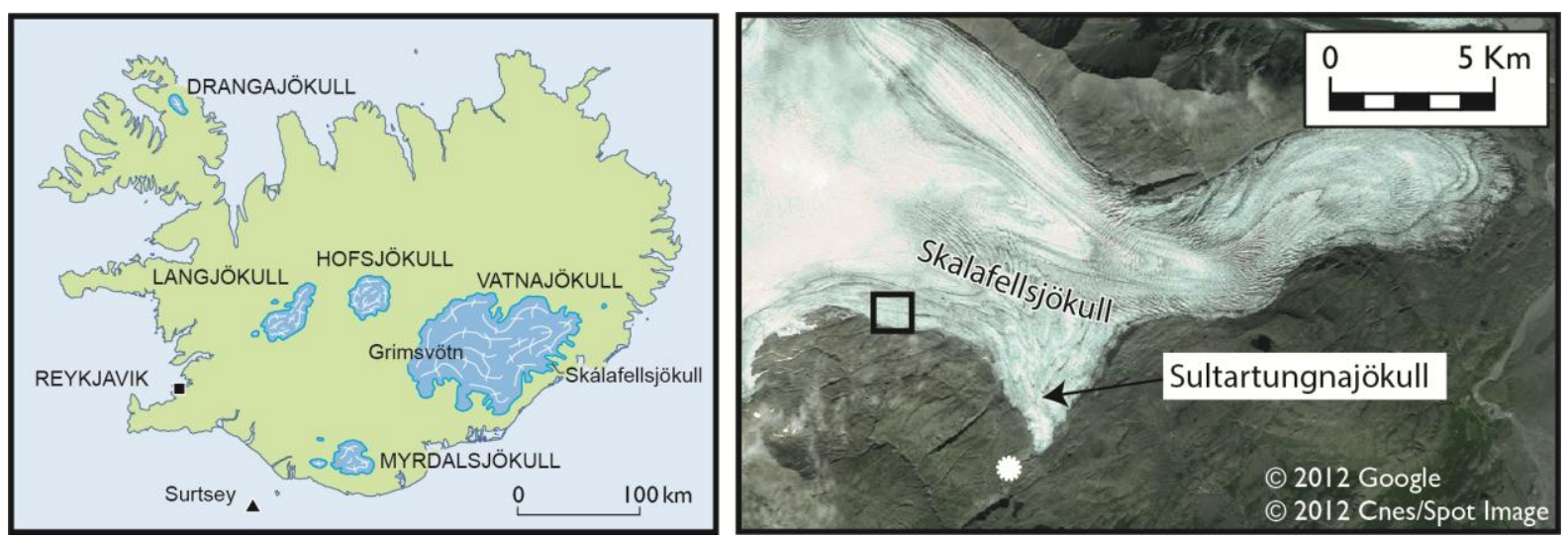

Figure 2

The bridge where the camera was installed. The circle marks the camera position.

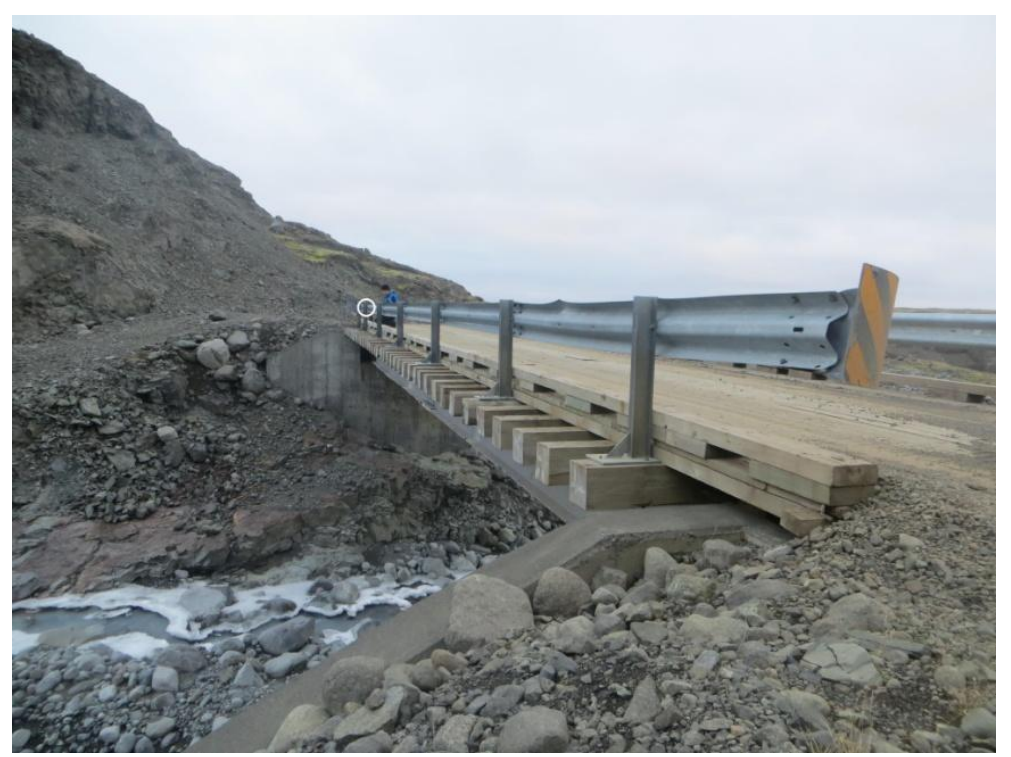


Figure 3

State of the river at (a) February high water (13:10 on 25 February 2013; estimated flow 3.81 $\left.\mathrm{m}^{3} / \mathrm{s}\right)$; (b) low water with river visible (17:10 on 3 March 2013; estimated flow $\left.0.39 \mathrm{~m}^{3} / \mathrm{s}\right)$; (c) September high water (18:45 on 23 September 2012; estimated flow $3.09 \mathrm{~m}^{3} / \mathrm{s}$ ); (d) very low flow with river obscured by snow (13:10 on 3 February 2013). The change in camera orientation between (c) and the later images was caused by reattachment and correction was made prior to analysis. Image (c) also shows the effect of rain on the camera lens.

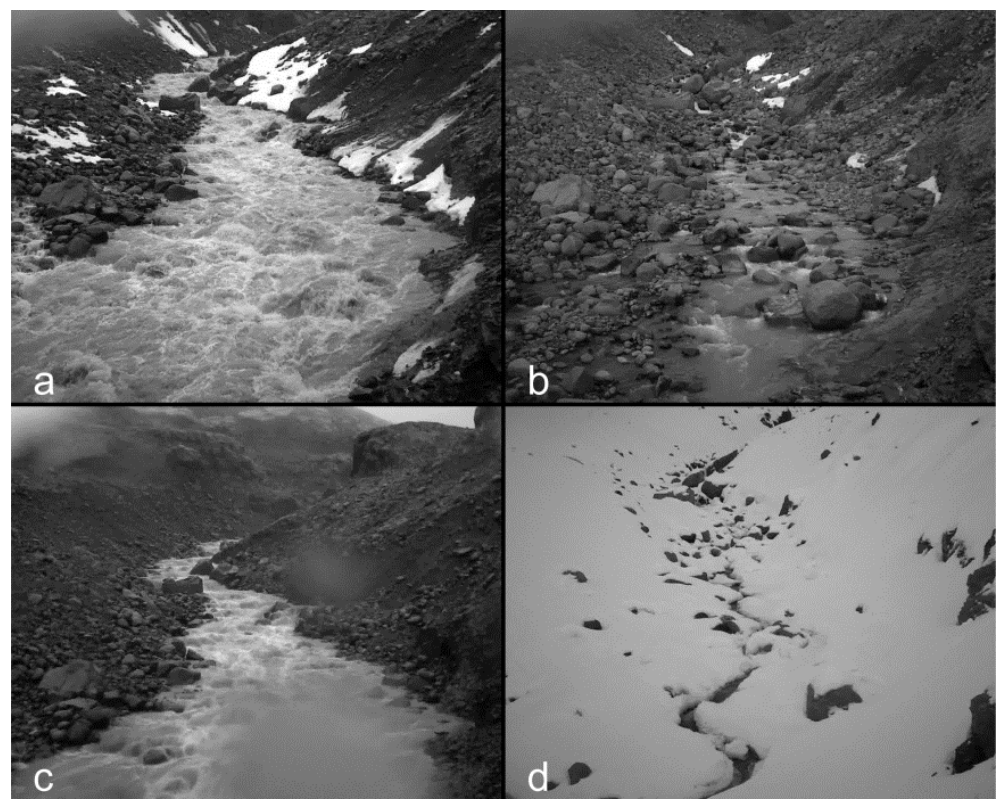

Figure 4

An image captured by the camera, with the five regions of interest for estimating flow marked.

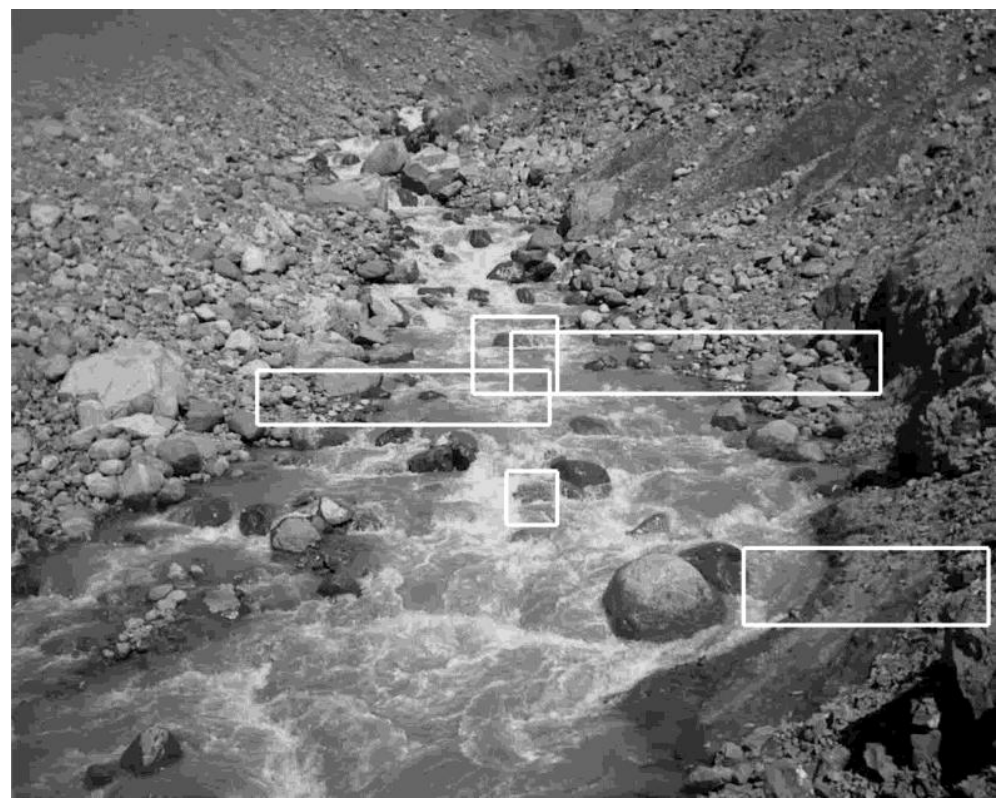


Figure 5

Finding water margin position at low flow and high flow in two regions of interest. The curves shown are parabolas fitted to selected edges. The output is the x-coordinate (left images) or ycoordinate (right images) of the centre of the fitted curve.

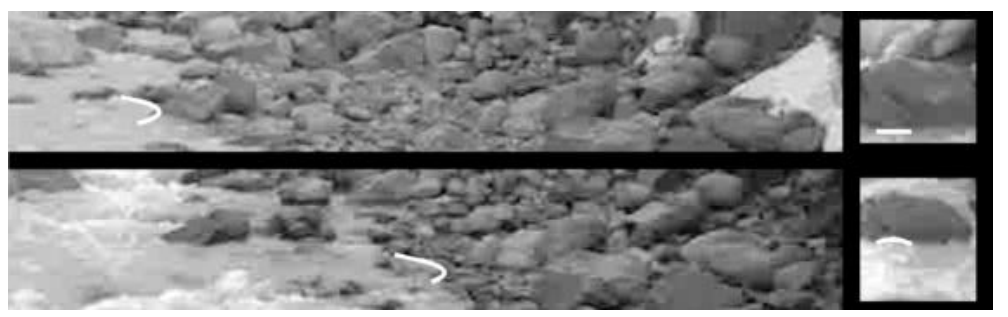

Figure 6

Simplified camera geometry for estimating water level. We assume that the image $y$-coordinate of the projected edge between the water and the boulder surface is linearly related to the water height. This is a good approximation because the angles $\alpha$ and $\theta$ are both small. Since $\alpha$ is less than $1.5^{\circ}$, the relationship between image position and position on the tangent plane to the boulder, shown dotted, is very close to linear. The error in measuring the difference between high and low water levels caused by the boulder's curvature is $A B$, which is equal to $\tan \theta$ multiplied by the line-of-sight discrepancy $B C$. In our case $\theta$ is less than $10^{\circ}$, and for a smooth boulder $\mathrm{BC}$ will be small compared to its height. The departure from linearity in the relationship will therefore be small compared to other possible sources of error. A similar argument applies to the measurements on the river banks, where the angle between the line of sight and the water margin is again small.

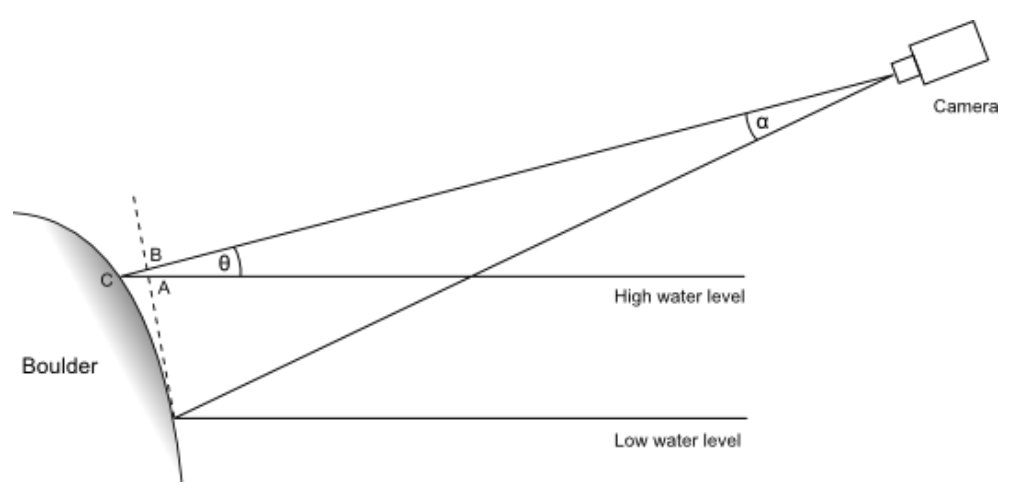


Figure 7a

The shadow of the camera position (circled), together with the known sun position at the time of the image, can be used to obtain a precise direction corresponding to a pair of image coordinates. This allows the camera's azimuth and elevation to be accurately estimated.

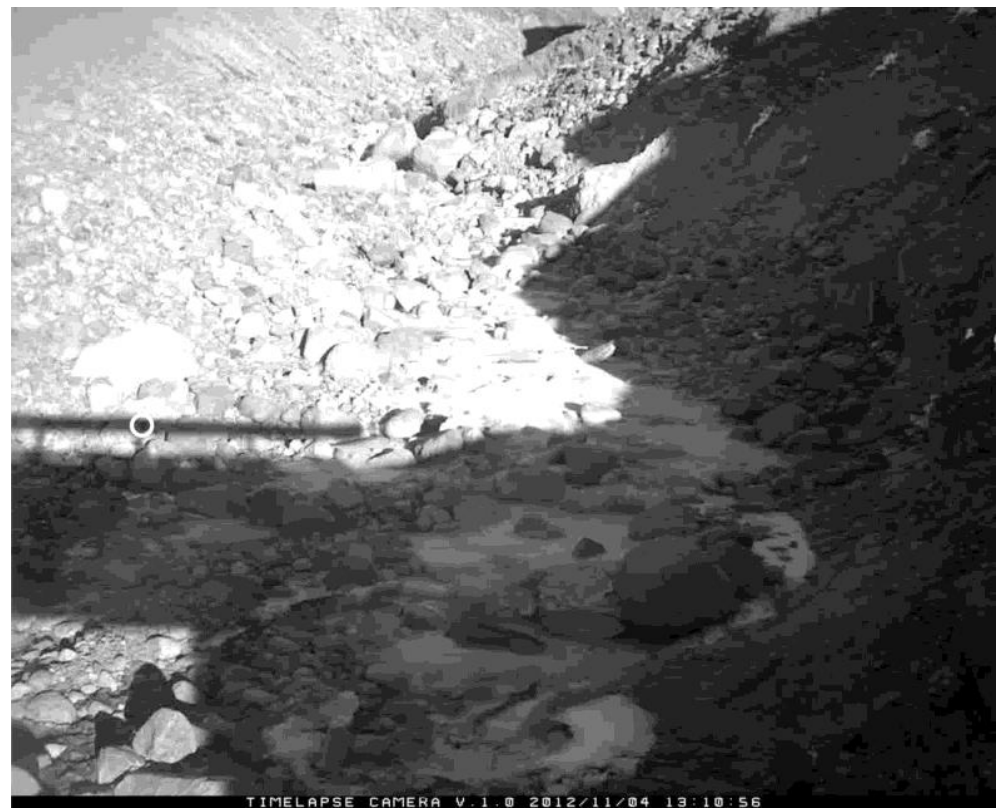


Figure $7 b$

The camera's known location and orientation allow its field of view to be mapped onto a digital elevation model (DEM). The camera's position is indicated by the asterisk, and its field of view by the three connected lines. The river course and glacier tongue are also indicated. The area shown is $1 \mathrm{~km}$ square, and the contour interval is $10 \mathrm{~m}$. The DEM is from the ASTER experiment aboard the Terra satellite, which has a spatial resolution of about $30 \mathrm{~m}$. (ASTER GDEM is a product of METI and NASA.)

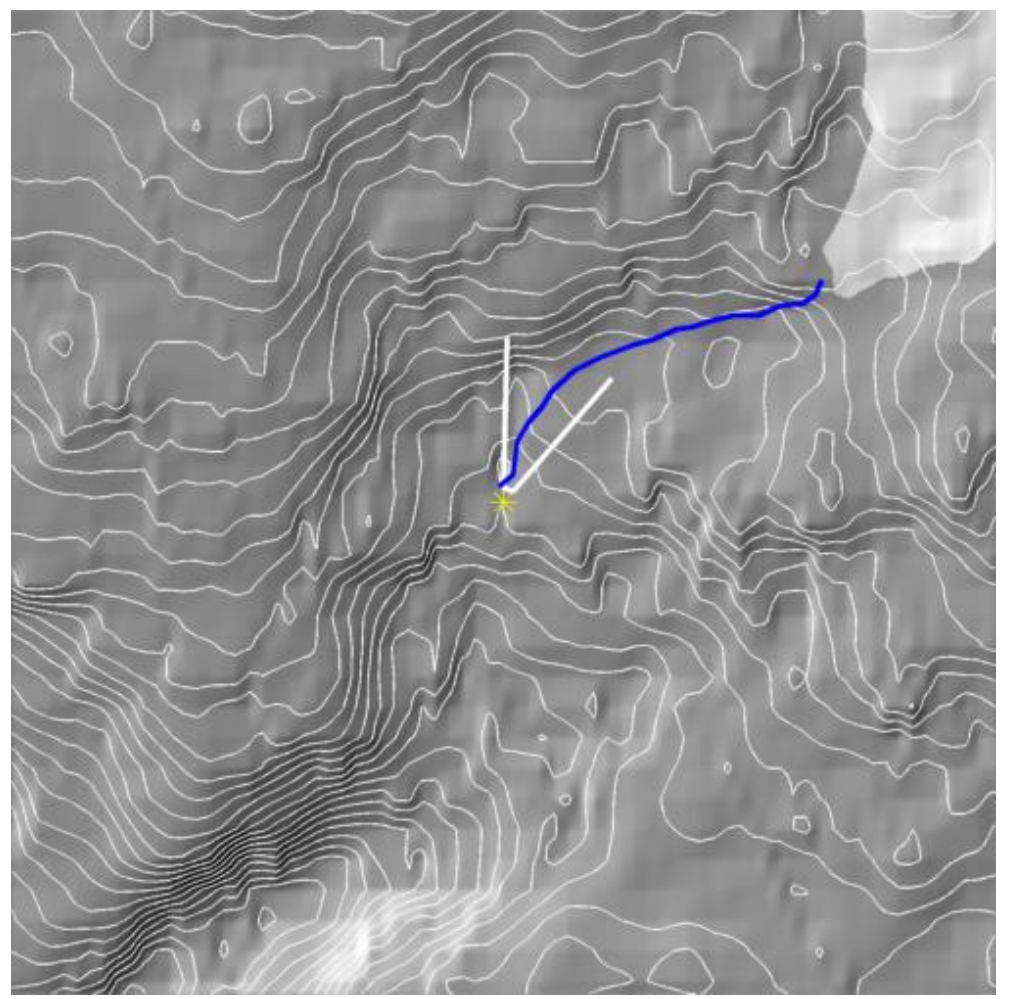

Figure 8

The estimated river discharge (heavier curve) and glacier temperature (lighter curve) for the study period, plotted against day of year from September 2012 to July 2013.

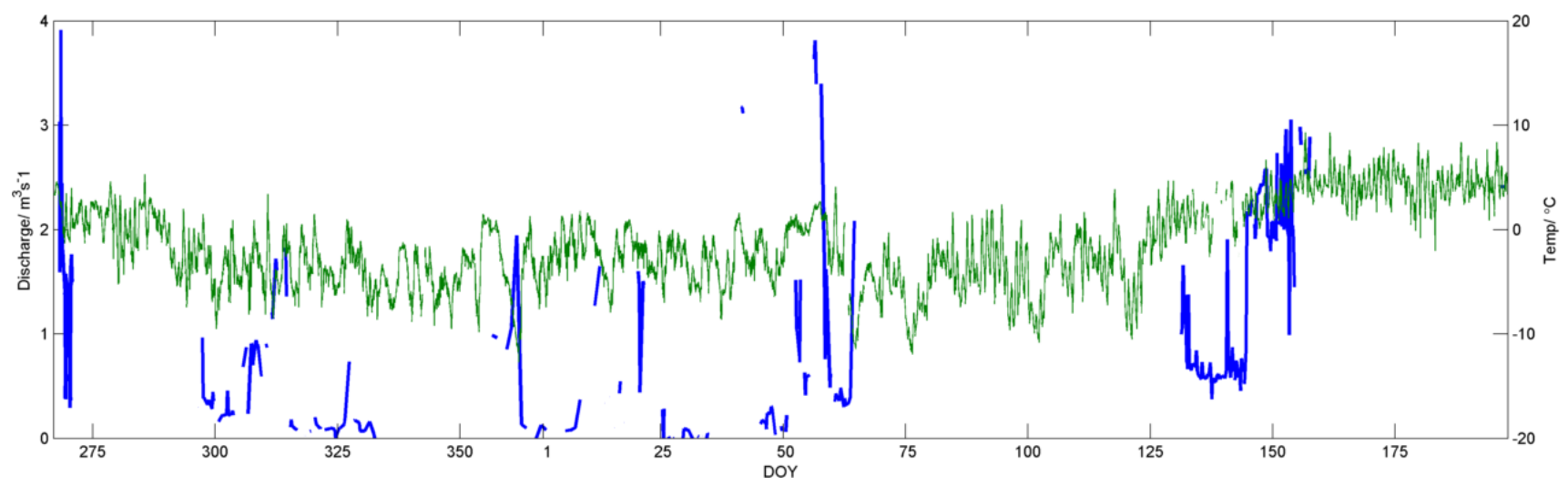


Figure 9

Diurnal changes: (a) Average discharge and air temperature at 4-hourly intervals for the different study periods (Late Summer DOY 267-290, Autumn 291-4, Winter 5-64, Spring 131-144, Early Summer 145-196); (b) Illustrating 2 days of a diurnal record when all 6 time periods are visible (DOY 152-154); (c) 3 days of a diurnal record recorded at 15 minute intervals (DOY 268-270). The error bars in (b) show one estimated standard deviation of the noise above and below the curve.

(a)

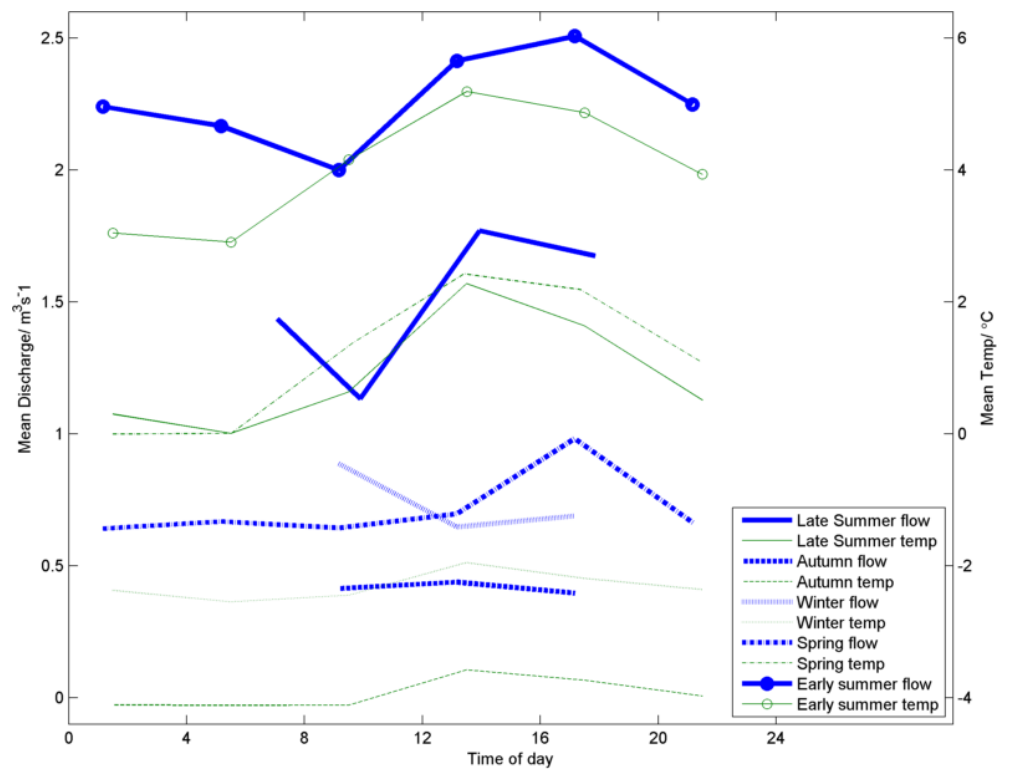

(b)

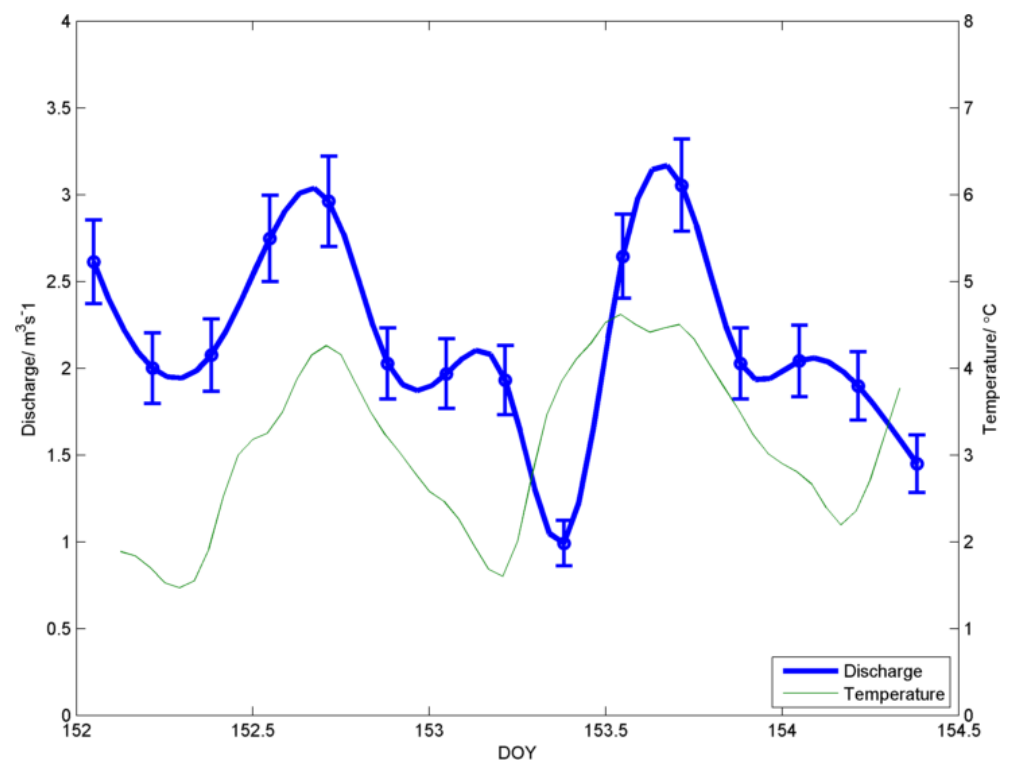


(c)

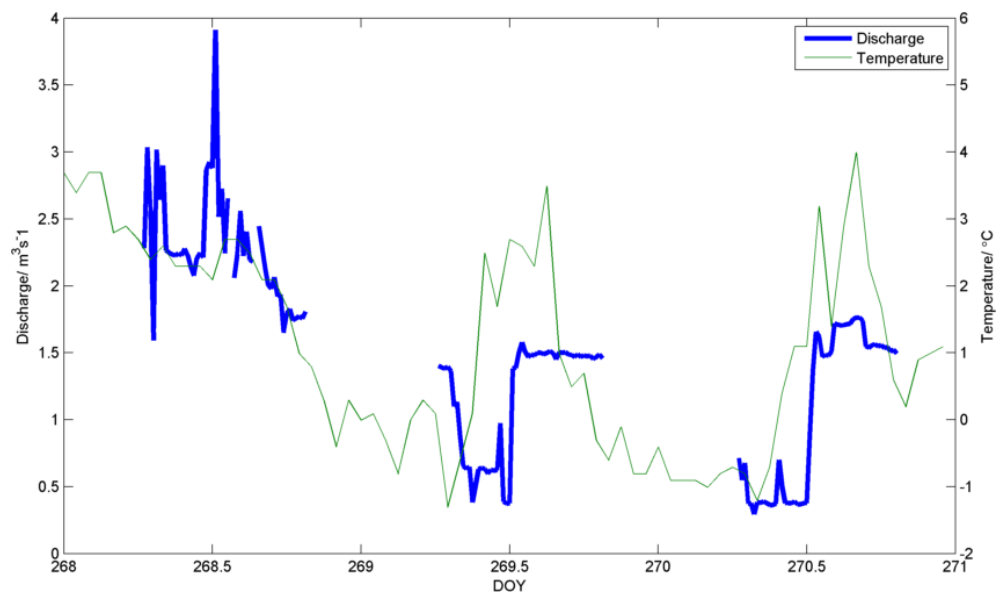

Figure 10

The relationship between mean daily air temperature and mean daily discharge for the different study periods. The periods are as for Figure 9a, except that Early Summer and Late Summer have been combined. The slanting line is a least-squares fit to the Summer data points.

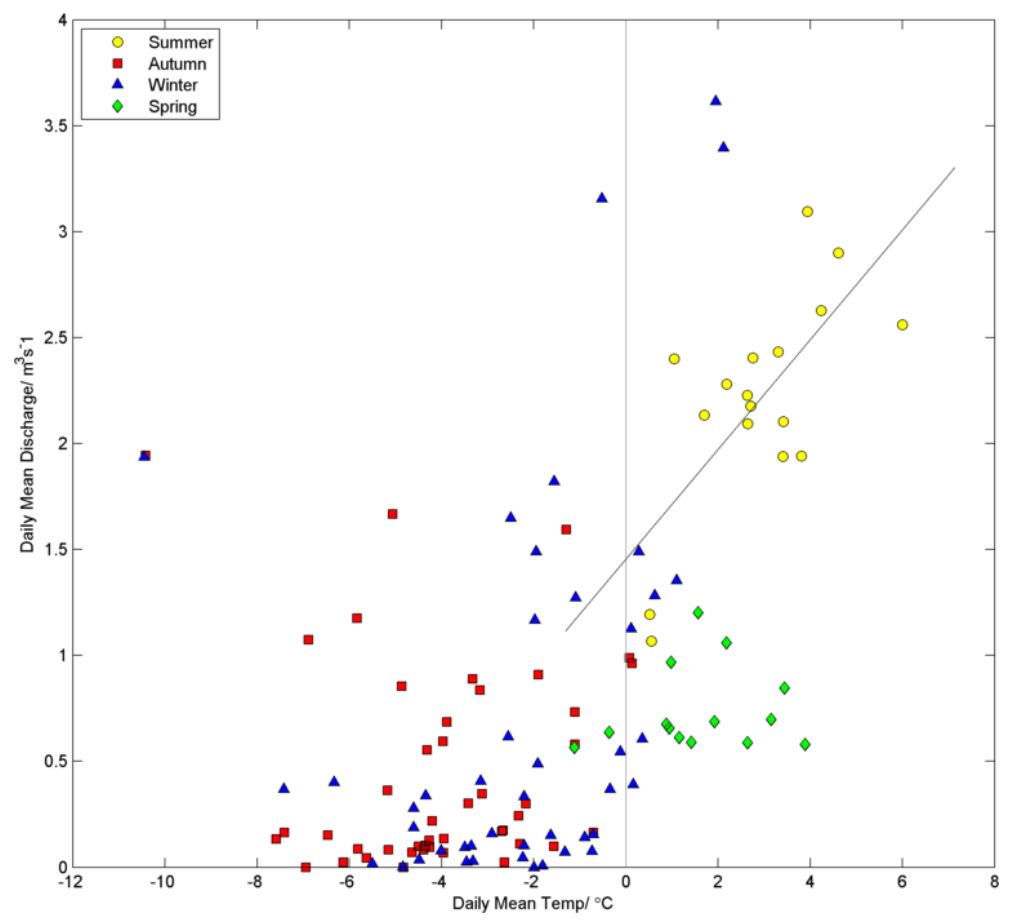

